\title{
A lírica do pelourinho ${ }^{1}$
}

PRISCILA FIGUEIREDO ${ }^{I}$

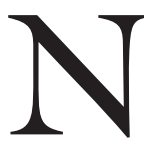

UM FILME de Woody Allen [Meia-noite em Paris, 2011], uma jovem americana rica e bonita quer chamar a segurança do hotel (o Hilton de Paris) porque dá falta de seus brincos de pérola e começa, com o apoio da mãe, a desconfiar da arrumadeira. O namorado escritor intervém e diz que não há provas suficientes que justifiquem essa medida. A moça, por sua vez, replica que a serviçal não tinha sido lá muito simpática de manhã e, sentindo-se cada vez mais contrariada, dispara que o pai dela (o qual já sabemos ser republicano) tem toda a razão em julgá-lo comunista. Rimos com o que parece um exagero e também por outros motivos, que não vêm ao caso agora. Acresce que o rapaz, que se preocupa com o destino da camareira, ausente da cena, é quem tem de fato a culpa no cartório, e é por isso também que se vê obrigado a intervir (e por fim reparar o dano). Nem por isso, no entanto, seus argumentos deixam de valer para nós, que sabemos de tudo que se passa. Pois é razoável dizer que falta de simpatia (concedendo que tenha havido) e a posse das chaves do quarto não são provas conclusivas para incriminar uma criada e não lhe dar o benefício da dúvida. Tampouco é comunista, ao menos de um ponto de vista mais clássico, digamos, quem se dispõe a lembrar isso. É mais o caso de falar em razoabilidade, ponderação, certo sentimento de justiça - até mesmo "sensibilidade democrática" poderia ser desnecessariamente especificador. Mas, parece-nos dizer o diretor do filme, no ponto em que está o conflito de classes nos Estados Unidos, qualquer concessão de direitos individuais aos mais pobres (mesmo que exógenos, como a criada de um hotel francês) pode ser lançada na grande e útil vala comum diligentemente aberta e nomeada de "comunismo" pela direita de lá etc.

No último livro de Francisco Alvim (2011), o poema "Histórias de neto" traz uma anedota parcialmente similar à do episódio referido. A semelhança de situações pode nos levar a concluir que em qualquer parte do mundo a empregada, quando existe, é, como os mordomos nos romances policiais, se não a culpada, sempre aquela de quem se suspeita primeiro quando se dá pela falta de qualquer coisa. Nesse caso, ela de fato cometeu um delito, mas não aquele imaginado por seus senhores, o que propõe novas complicações e faz rir de outra maneira:

Histórias de neto

São muito chatas

Mas esta vale a pena

A babá

mocinha treze catorze anos 
resistiu quanto pôde

mas acabou que

confessou tudo

Só que o tudo era outra coisa

muito pouco

quase nada

cinco reais um lençol um quilo de arroz

o Cartier, negou

Ele três aninhos só ouvindo

e

de repente:

(nunca vi criança tão inteligente)

Mas que perigo

podiam ter roubado

a minha chupeta

A operação pela qual o título é ao mesmo tempo o sujeito do primeiro verso, "São muito chatas", é não apenas uma operação de contenção formal, familiar ao leitor de Francisco Alvim, como também permite multiplicar hipóteses e imaginar dois tempos. Em destaque apenas "Histórias de neto", nosso espírito é preparado para uma anedota simpática, que está por vir, provavelmente a ser contada por um avô orgulhoso das peraltices astuciosas do descendente. A qualificação "são chatas" já é, no entanto, problematizadora pelo distanciamento que supõe. A linha seguinte, "mas esta vale a pena", reconhece a singularidade da anedota no seu gênero e o alcance para além do ambiente em que se originou. Talvez quem a vá narrar não seja o simpático coruja que esperávamos, e antes alguém que lhe tenha ouvido o caso, um parente ou amigo. Nada impede também que estejamos diante de um avô mais refletido ou bem-educado, que, conquanto reconheça a impolidez de azucrinar ouvidos alheios com uma narrativa doméstica, em que só os implicados costumam achar graça, vai divulgar uma - entre muitas outras que decerto prefere manter na alçada familiar - por julgá-la passível de apreciação em círculos mais amplos.

Por seu turno e conforme a perspectiva, o verso entre parênteses “(nunca vi criança tão inteligente)" ora pode reforçar que o locutor conhece a família, dando-lhe caráter testemunhal e aumentando a veracidade do relato, ora pode indicar que se trata do avô, sim, e que esse mal se contém no desvanecimento refreado pelo primeiro verso do poema. Desvanecimento, porém, que não chega a produzir agora dissonância ou gafe no conjunto, que é sempre atento às normas da conversação. Seja conhecido, amigo, parente distante ou próximo - o narrador é um sujeito bem-educado.

Sob qualquer uma dessas hipóteses, o procedimento é o mesmo no que diz respeito à hierarquização dos papéis e dos acontecimentos. A historieta começa com o caso da babá, cuja exposição é sintética e se inicia sem preâmbulos, para imediatamente encaminhar o desfecho e não fatigar o ouvinte - "resistiu 
quanto pôde / mas acabou que / confessou tudo". O suspense, criado por frases que bem poderiam ter como referente uma situação de tortura - e talvez tenham em certo sentido -, é dissolvido pelo teor da confissão, que já nos instala em outro clima. E o que se passa com a jovem, à medida que evolui o relato, apenas dá oportunidade para que venha à luz a esperteza do bebê, que encerra o episódio com chave de ouro. Essa tira a primazia do primeiro acontecimento, por fim mero fundo de cena, no centro da qual vem se destacar a genial criança, cercada dos mais velhos, estatelados por comentário tão irônico e certeiro ter sido proferido por lábios tão verdes. Um tal quadro nos é facilmente sugerido.

O nada confessado pela menina e de que fala o narrador é na verdade tudo que guardava em si, a história e a memória do seu delito, os pequenos objetos roubados. Esse tudo, no entanto, não era o tudo, muito mais graúdo, do patrão, isto é, o relógio Cartier. A reversibilidade entre tudo e nada ilustra a dança dos pontos de vista, e sua representação cativa: é ralentada - em comparação com o andamento mais brioso do conjunto - e escalona cuidadosamente, em cinco versos, a passagem de um polo a outro. Ao cabo do processo, esses abstratos e absolutizantes pronomes indefinidos acabam por reverter nas coisinhas - pálidas mas mais concretas - da empregada:

confessou tudo

Só que o tudo era outra coisa

muito pouco

quase nada

\section{cinco reais um lençol um quilo de arroz}

Tanto espremeram a moça que ela expeliu o que guardava, umas bobagens - é verdade que, num aperto dessa ordem, qualquer coisa pode sair, ela sempre haverá de sair, pois a coisa forçosamente se cria ou ganha substância; o importante é que se escolha a classe de pessoa que a produzirá, como na tortura, fim em si mesmo, expediente maníaco e já desligado de toda realidade, ou propósito verdadeiramente investigativo. No caso, a energia aplicada pelos patrões na coação é desbaratada pelo baixo valor dos objetos enumerados, que tiram ao furto toda a seriedade dramática. Então era só isso? E nós assim, nervosos, para nada? O efeito é, literariamente, uma mudança de gênero, pela qual vamos dar na comédia ligeira. Produz-se, assim, um anticlímax e é quando menos esperávamos que sobrevém a observação solerte da criança e sua preocupação galhofeira. Foi pelo nada da babá que o bebê foi picado, sentindo-se impelido a reconhecer que, pela categoria dos artigos subtraídos à casa, bem poderia figurar entre eles a sua chupeta, também uma ninharia, do ponto de vista dos adultos, mas para ele algo fundamental, como para a empregada o lençol e o arroz.

Com essa tirada, de fato impagável, tudo se ilumina e fica mais leve, realizando o gênero que o título do poema prometia. No entanto a "história de neto" como um todo, por tão faceira e por assim hierarquizar as coisas e enquadrar o caso, não apanha desse todas as articulações, isto é, tudo aquilo por que 
passou a adolescente, que, já pela idade, esteve tão desamparada. Não houve interesse em mimetizar, em dar representação verbal circunstanciada ao sufoco de quem foi posto contra a parede, de quem deve ter sentido o maior medo e humilhação e aguentou o mais que pôde (resistiu tudo) até confessar o seu tudo. Entre a sua resistência e confissão vai um processo pelo qual a necessidade que a fez pegar umas insignificâncias debate com a necessidade do emprego e com sua consciência moral, ante a qual afanar um mantimento qualquer já devia ser vexaminoso. Não seria preciso roubar um Cartier. E, no entanto, ela deu a título de sua mais dolorida declaração o que poderia perfeitamente não ter vindo à luz porque, sendo tão desimportante, simplesmente não a merecia. Esse sofrimento, porém, foi arquivado pelo conjunto, verdadeiramente pau-brasil, do poema.

$\mathrm{O}$ que nos autoriza a nos deter sobre ele e a fazer tais considerações se a esteira rolante da construção já o põe longe dos nossos olhos, diante dos quais exibe agora uma criança matreira, naturalmente descuidada dessa ordem de implicações? Ora, a peça, se não é mimética em relação aos apuros da empregada, é perfeitamente mimética em relação ao fato, comuníssimo na vida brasileira, de que esses apuros costumam passar batidos - ficando... esbatidos, palidamente fixados. Incriminar assim uma doméstica, mesmo na ausência de provas, indícios, é algo visto como natural, legítimo, isso quando não a levam direto à delegacia (o que foi prática comum no país, com recurso aos mesmos instrumentos de tortura que serviram para punir o escravo). E, uma vez provado que ela não tem culpa no cartório, fica tudo por isso mesmo. Ou seja, isso pode passar batido por pessoas educadas, não provincianas em mais de um aspecto, experimentadas nas formalidades da conversação e atentas aos interesses do ouvinte, como são as do poema, mas nem por isso, quando se trata dos pobres, atentas às formalidades básicas do direito penal, como o direito de defesa, o respeito à dignidade da pessoa humana etc. E a esse vestíbulo de tribunal de exceção estão e estiveram sujeitas incontáveis meninas, tão misturadas a nossas coisas (com tão mais intensidade e freqüência do que as criadas de hotel) a ponto de ser antes irresistível para estas, coisas, que saltem para sua mão.

Convém lembrar, no entanto, que mesmo quando se trata de aplicar a Lei, pode-se não estar em plena conexão com a realidade objetiva: "Leis // Sempre registram minha / falta // A lei não entende / Não sofre a meia / sombra do / sol". Sol sem sombra não é sol, é imitação insuficiente desse, pois não cobre a multiplicidade e as "sombras" da práxis humana. O sol esclarecido das leis "não entende", já perdeu sua inteligência de origem porque já fala de um ponto de vista distanciado do cotidiano pulsante, sempre renovado. A solução, no entanto, para fazer frente a uma impostação dessa ordem não deveria ser a desuniversalização na aplicação da norma, o que pode estreitar ainda mais sua operacionalidade, agora pelo papel muito mais ativo de interesses particulares, desrecalcados. A propósito de tal tensionamento, aqui presente, como se pode notar, e que a cada livro do poeta ganhou mais e mais corpo para culminar no conjunto -romanesco e polifônico - dos poemas de Elefante, leia-se o ensaio de 
Roberto Schwarz, "Um minimalismo imenso", em sintonia com as faixas de sol e sombra dessa poética. ${ }^{2}$

Quanto ao poema com que começamos este artigo, há ainda elementos internos, da própria construção, parcimoniosos, sutis, é verdade, que nos habilitam a "raspar a casca do riso para ver o que há dentro", conforme a recomendação de Machado de Assis. É o caso do pequeno mas nítido vocabulário da tortura a que nos referíamos. Haverá parentesco entre ele e a referência explícita à escravidão naquele que é, segundo minha opinião, um dos mais notáveis poemas desse livro, "A mão que escreve"? Ainda que a noção de grande possa ser relativizada pela concorrência de outras, tão ou mais interessantes para o leitor atento às perspectivas abertas pelas vanguardas. É a isso que se refere Zuca Sardan, na criativa orelha do livro, quando opõe magistral e revolucionário. Esses termos qualificariam faces diferentes do livro, a trágico-lírica e a irônico-galhofeira, a qual pediria, para a plena realização de seu efeito estético e crítico, um extremo ativismo da parte do leitor. Creio que o poema em questão, que pertence à vertente lírica, indica um processo pelo qual se infundiram nela aspectos da outra vertente, que Roberto Schwarz (2013) chamou de “crítico-realista”. E nesse ponto haveria uma inovação, não só dentro de sua própria estética, mas em relação ao modo de apropriação da herança drummondiana.

A mão que escreve

O tronco nu

contorce e grita

na flora obliqua

O ar respira

a dúbia aragem

Na carne escura

a dor que surde

Aqui agora

tantos olhares

Presos no lírio

do pelourinho

Látego e nádega

Um corpo cego

emparedado

na própria história

Ecoa vivo

o meio-dia 
o ouro falso

da vida falsa

Fezes e mijo

Suor e sangue

Carne tão nossa

A mão apócrifa (grifos meus)

Fulgor, aragem, grito. A tônica em $i$ repica em palavras-chave, faz vibrar a paisagem, atiça fogo e estridência. Antes mesmo que se fale em "meio-dia" e "ouro", já vemos tudo sob um solviolento (como lemos no poema seguinte). $\mathrm{O} i$ aqui é amarelo. Mas a atenção é também logo fisgada pela expressão "lírio do pelourinho", que conjuga palavras com referentes tão distintos como o céu e o inferno, o belo e o grotesco, ou o ócio (do lírio que não tece nem fia, conforme o comentário bíblico) e o trabalho compulsório. Formam, no entanto, uma quase paronomásia, parecendo o termo menor ter sido extraído do maior e supor um terceiro termo, oculto - lírica. A lírica do pelourinho? Não ponhamos a carroça na frente dos bois, mas antes notemos o curioso relevo que assumem as proparoxítonas na construção: látego, nádega, sonoramente muito próximas, com variação apenas na primeira consoante, e apócrifo. Proparoxítonas são palavras raras na língua portuguesa, razão por que são acentuadas. O que é pouco frequente numa língua soa, portanto, menos natural aos seus falantes e, numa construção tão bem travada como a que está em questão, se um som mais exótico vem bater um pouco demais no ouvido (e pode ser aquele, interno, de quando só lemos com os olhos), é porque ...está querendo entrar. Mas ele quer e nosso ouvido, antes descuidado e calmo em razão do entra-e-sai da música familiar, logo se põe em guarda e manda descer o portão. O som continua a bater e, com isso, todos os faróis da torre ficam sobre ele. Em suma, o efeito produzido por esse conflito é prestarmos mais atenção no significante que no significado, como se entrasse um pouquinho de ar no vácuo que os prende. E a questão deve ser por que se estimula isso de nossa parte.

A justaposição do parnasiano "látego", de evocações épicas, e do eufemístico e científico "nádega" confere certa abstração à cena (até esta se sujar de "fezes e mijo"). Ao mesmo tempo, a semelhança mórfica entre os termos tem algo de uma ironia do destino, pois eles de fato dizem respeito a coisas objetivamente relacionadas, sugerindo um provérbio conforme o qual para toda nádega, e nádega negra, no caso, haverá sempre o látego. A justaposição perfaz ainda um verso em ritmo composto por um momento forte e dois fracos, tá ta ta, que é peculiar às proparoxítonas. Látego, nádega -tá ta ta, tá ta ta é o que ouvimos, e por ele devemos escutar, ou imaginar, as chicotadas infernais e infinitas, escoando-se como as horas de um relógio, com o intervalo necessário entre uma e outra. Ou sentir antes o deleite do poeta em escandir tais palavras em sequên- 
cia, desgarrando-as por um momento do contexto atroz a que se ligam, e lhes enfatizar o ritmo bem marcado? Talvez as duas coisas num poema que conjuga assunto grotesco e grande encantamento audiovisual.

O anônimo e parcial tronco, metonímia do corpo, aqui tão destituído de humanidade como um pedaço de madeira (tronco também é o cepo em que se amarra o escravo para castigá-lo), ganha inadvertidamente uma vibração nova pelo contorcimento e pela vizinhança com a flora oblíqua, com a qual se confunde e como que se vegetaliza. É o torso que se torna oblíquo e, pela dor, se entorta para fora do pau a que está preso, atravessando a paisagem e o olhar, ou o olhar de quem o via, cotidianamente, na praça de espetáculos da escravidão. É esse corpo (cego, escuro e mudo, para usar adjetivos pelos quais essa lírica tem um gosto obstinado desde o início) a verdadeira trave na visão, ou a verdadeira pedra no caminho do poeta, pedra que sidera o olhar, o impede de avançar - o deixa mesmo paralítico, como vamos encontrá-lo na composição imediatamente seguinte, não por acaso chamada "Diante", quando, em face do espelho, se horroriza com a "história tão obscura / [...] deste país".

Suspensão diferente presenciávamos em "Aberto", de Elefante (2000), no qual o olhar caminhava na trama da luz e estacava "no ar do ar / na luz da luz". Ou mesmo no esplêndido "Afrodite", no livro presente. Nesse caso, a suspensão é do tempo, retomando aquele goethiano Detém-te - és tão belo, dirigido ao instante: "Azul sonoro / da hora que passa / e que para". Ainda que provavelmente constitua a descrição de uma obra pictórica, tal peça incide numa linha de questões muito peculiares a essa poesia. Talvez se possam ler os dois últimos versos como aposto de "azul sonoro": a palpitação, apreensível mais pelo ouvido, da hora viva e que passa, ou passou, conserva-se na hora que para e que, parada, torna-se visivel, azul extenso, sobre o qual os olhos se movimentam. Azul que tem presença e surde - por ele se escuta o coração, sonoro, do instante, o qual, assim fixado, se livrou de ser tempo arquivado, tempo morto. A fusão projetada dos sentidos da visão e da audição, também cara à lírica em questão, dedica em $O$ metro nenhum um lugar próprio à pintura.

Quanto a "A mão que escreve", creio que é de outra ordem a sinestesia de "Ecoa vivo / o meio-dia" - se o lermos mais como sol do meio-dia que ecoa, sol que ecoa, do que como hora que ecoa, embora evidentemente também o seja. É sob o meio-dia -vivo - que a cena transcorre, a qual nos apresenta o olhar preso "no lírio / do pelourinho". Essa luz que soa no aqui agora e que não cessa de incidir, não é, por certo, da mesma natureza daquele "azul sonoro" que analisávamos, estando mais para o "sol que não se põe" do espetáculo. ${ }^{3}$ Sol que não fecha as pálpebras e diante do qual os olhos também não descansam - ele é o núcleo pulsante da produção material.

No pelourinho não está aprisionado apenas o tronco inerte, como tam- 
bém a multidão que o contempla e o olhar interno do eu lírico, o projetor da cena e da imagem da escravidão, olho que não é testemunha e então fabula, repropondo, para nossos olhos-ouvidos internos, a cena como espetáculo. Essa cena deve ser recuperada (é tal recuperação "o mínimo ético" de que se fala no livro, a nossa minima moralia, sem a qual não haverá vida correta?) como um chiado ininterrupto e, no entanto, disruptivo, que não dá descanso a quem escreve. No que é ininterrupto, embota a percepção, pois reproduz a história que não repara os sofrimentos que causou e se repete ("a ferida supura", como se diz no fosfóreo "Presídio"); no que é disruptivo, pode fazê-la avançar para além da estagnação em que a encontramos no poema "Meio do caminho", retomada ultraconsequente do poema mais famoso de Drummond.

Látego, nádega, apócrifo - essa tríade excêntrica e culta conta uma história comum, a da divisão do trabalho social sob o capitalismo, das peculiaridades que ela veio a adquirir entre nós e da cumplicidade de boa parte de nossa produção ideológica e artística com a manutenção e defesa da escravidão. O título da composição põe em foco, porém, mais o trabalho intelectual que o trabalho material. A ênfase está no acerto de contas do escritor consigo mesmo e com esse "corpo escuro" - ponto cego em que se reúne o objeto supliciado, o sujeito que o suplicia e o "voyer" da cena - redescoberto, ao fim, como "carne tão nossa".

A carne é nossa, a mão é inautêntica - pois o que se vê não vendo produz estranhamento de si, do próprio corpo, mas também do país, como em "Diante". Reproduzo as duas últimas estrofes:

Tal fora uma cobra

sucuri enorme

no charco mais fundo

da densa floresta

nestes brasis

de sombra e de sol

violentos

E o tempo dele

de fora e de dentro

fora

o movimento de um corpo

nas águas mortas de um morto

O corpo, que faz confinar mundo e interioridade e se move, prova de que se está vivo e se toma pé no mundo (para falar à maneira da fenomenologia), é no entanto um corpo que avança, qual uma sucuri, "nas águas mortas de um morto" - morto o país? A história? Qual história? O ar, diferentemente do que 
ocorre nos poemas mais solares e venturosos (veja-se "Sonoro"), aqui não circula. Como em "Presídio", se poderia antes dizer "Tanto tempo / faz / que não respiro”.

Talvez essa víbora, enorme e primitiva, história inconsciente de si dentro e fora do sujeito - será então história? - venha ser a mesma que dá título ao poema jocoso que lemos páginas antes:

a que continua viva

depois de morta

é a que pica mais forte

Por isso é mister

esconder o pau

(e não mostrá-lo

como pensa o vulgo)

Assim nunca saberá

a cobra

de onde baixa o porrete

eternidade afora

O povo admira quem mata a cobra e mostra o pau. Ocorre que a da espécie em questão é manhosa, pica mais forte depois de morta e, mesmo nesse estado, pode adivinhar o cacete e a mão que o segura, revidando de maneira ainda pior do que o faria se estivesse viva. Por isso, aconselha-se aqui, não mostre o pau. Sem duvidar da cientificidade que possa fundamentar a advertência, não deixa de animar a esta uma preocupação de natureza supersticiosa, segundo a qual, ante uma fera desse tipo, mesmo liquidada, é prudente ser discreto e evitar vangloriar-se. Pode-se ser punido em razão do excesso, de uma espécie de hybris - e quem o punirá é a própria cobra assim abatida e de vibrações diabólicas.

Trata-se da recomendação, algo cifrada, dada a quem está encarregado de dar cabo de uma criatura vista como muito perigosa? Uma recomendação a um pau-mandado qualquer, que deve eliminar alguém a quem o rancor acumulado torna-o o mais perigoso dos seres, capaz, contradição gritante, de continuar vivo mesmo morto? Assistimos a uma operação pela qual aquele que com razão odeia, e odeia de ódio secular, é transformado em besta infernal, que, mesmo depois de ser dominada, é necessário... dominar? Agora com a astúcia necessária de quando se lida com seres mais metafísicos. Talvez. Essa composição se segue àquela, ultraconcisa e de caráter sentencioso, na qual "Bochecha // ofereça a outra" é tudo que lemos. Pela vizinhança (termo, aliás, que intitula outra peça no livro), podemos pensar que a criatura referida não é do tipo que cumpriria a divisa cristã acatada, a sua maneira, pelo dominador. Esse decerto desejaria que 
ela fosse posta em prática pelo dominado, que assim não picaria nem em vida nem em morte - é verdade também que o mandamento de "Bochecha" poderia ter valor civilizatório e evitar a rinha entre diplomata e coronel, com assassinato de um deles, no poema que o antecede, "Entranhas". Por aí podemos sentir um pouco o meio ambiente do livro, em que a ordem e a vizinhança entre as peças não é aleatória, aumentando-lhes a ressonância e variando a perspectiva de sua leitura. Vale também aqui o que Roberto Schwarz (2013, p.134) comentou em relação a Elefante: "A sequência dos poemas é fruto de muito cálculo, tem o caráter propositado da montagem e obedece a maquinações de encenador [...]".

Voltando a "Cobra", nada opõe-se, por outro lado, a que a vejamos como a orientação de um poeta experiente, conforme a qual o artista não deve se gabar de seu êxito e ficar falando demais. A obra, que matou a pau a inexistente serpente (termo esse descosturado em "Balada", com as letras soltas, permitindo a inserção de outras sonoridades), nem por isso menos atanazante, pode ser por ela assombrada. Essa hipótese, que não elimina a crença num sortilégio, nos faz pensar sobre as relações na poesia entre forma e conteúdo, sendo esse a fera golpeada ou domada, ao menos provisoriamente. $O$ pau que não se mostra pode ser também o metro ausente e regulador, produto de grande internalização de ritmos, metro que tanto mais é audacioso e enquadra as potências selvagens quanto mais se invisibiliza. Mas esse enquadramento, às vezes referido como emparedamento (em "A mão que escreve" a cena se passa "entre as quatro paredes" de versos tetrassílabos), é problematizado na dialética entre o dentro e o fora do muito lírico "Quadro":

Algo que se apaga ou apenas transparece no espaço trancado de uma parede

E se parede não existe--

tudo

mera superfície de traço e cor?

De outro ângulo, a cobra "que continua viva / depois de morta" não participaria da mesma contradição articulada nos versos "vida / desvivida / vivida / sem viver", do poema "Agora"? Este como um todo sugere, no entanto, um lugar em que essas categorias, vida e morte, não estão sacrilegamente misturadas:

$[\ldots]$

Pensa

os degraus ilimitados

lançados do azul de um céu

profundo, distante 
Formas desvividas

Da vida

$[\ldots]$

Tais estrofes pertencem a uma composição complexa, no que grafa e no que não grafa, na letra e nos espaçamentos, que não cabe analisar agora. Algumas palavras apenas: a felicidade pode estar ligada à aragem que experimenta em seu rosto a criança onipotente, jogada para o alto pelos adultos, cena que Freud viu ser repetida nos sonhos de voo, nos quais alcançamos o céu. Sobressai a obsessão dessa lírica com a cor azul, cor que às vezes surge justaposta ao ouro, como na igreja barroca o azulejo português ao ouro da talha. Se é o "ouro falso" da riqueza assentada na mão de obra escrava, ela própria moeda de ouro, o olhar infantil desconhece e se deixa encantar. Esse momento está também preservado.

Semelhantemente ao Drummond de "Canto negro" (Claro enigma), prenhe de dor moral pelo passado escravista, projeta-se aqui o desejo de novas possibilidades perceptivas, de um novo modo de aparição das coisas ante o olhar: "essa nostalgia rara / de um país antes dos outros, / antes do mito e do sol, / onde as coisas nem de brancas / fossem chamadas".

\section{Notas}

$1 \mathrm{O}$ artigo presente é a versão integral (com poucas modificações) de texto publicado na revista Piami, n.62, novembro de 2011, "Francisco Alvim e a lírica do pelourinho".

2 Roberto Schwarz, "Um minimalismo imenso", Folha de S.Paulo, 10.3.2002. O autor depois reuniu esse artigo a outros em seu livro Martinha versus Lucrécia (Schwarz, 2013).

3 "Il est le soleil qui ne se couche jamais sur l'empire de la passivité moderne" (Debord, 1992, p.21).

\section{Referências}

ALVIM, F. O metro nenhum. São Paulo: Cia. das Letras, 2011

DEBORD, G. La société du spectacle. Paris: Gallimard, 1992.

SCHWARZ, R. Martinba versus Lucrécia. São Paulo: Cia. das Letras, 2013.

RESUMO - Este artigo procura analisar a mudança operada no último livro de Francisco Alvim, O metro nenhum, em relação às obras anteriores, sobretudo Elefante, nos quais os poemas líricos não tratam diretamente do "sistema de nossos constrangimentos sociais" (Roberto Schwarz), de que se ocupam em geral os poemas mais crítico-realistas do autor. A análise se concentra sobretudo numa composição como "A mão que escreve", em que ambas as tendências estão perfeitamente fundidas. O que favorece essa 
fusão é também a autoanálise do intelectual ante a pesada herança moral e social legada pela escravidão.

PALAVRAS-CHAVE: Lírica, Realismo, Intelectual, Herança escravista.

ABSTRACT - This article aims to analyze the change in the last book of Francisco Alvim, O metro nenhum, compared to previous works, especially Elefante, in which the lyrical poetry do not directly address the "social constraints of our system" (Roberto Schwarz), that the most critical realist author's poems deal with. The analysis focuses mainly a composition as "A mão que escreve", in which both trends are perfectly fused. What favors this merge is also self-analysis of the intellectual in the face of the heavy moral and social heritage of slavery.

KEYWORDS: Lyric, Realism, Intellectual, Heritage of slavery.

Priscila Figueiredo é professora de Literatura Brasileira no Departamento de Letras Clássicas e Vernáculas da FFLCH-USP. @-priscila.loyde@gmail.com

Recebido em 10.2.2015 e aceito em 27.2.2015.

${ }^{\text {I }}$ Faculdade de Filosofia, Letras e Ciências Humanas, Universidade de São Paulo, São Paulo/SP, Brasil. 